\title{
Occupational trends in the United States
}

\author{
Richard Pearson
}

\section{US government figures show just how rapidly employment patterns are changing.}

IN September last year the Employment column reported on the occupational changes expected in the United Kingdom over the period to $1990^{1}$. That study was unique in being based on the expectations of employers and as such it was able to explain many of the underlying causes of change. More frequently, however, economic models or statistical projections are used to map out future occupational change. Their utility is largely dependent on the availability of historical time series of occupational data, complemented by a variety of desk research techniques. The most developed statistical projections of occupational change are those produced biennially by the Department of Labor in the United States. One of the main outlets and uses of the model is in the production of the annual Occupational Outlook publication which details occupational and training profiles of over 750 occupations. The underlying model itself draws an extensive set of time series data on 150 in-

Table 1 Occupations with the largest job growth, 1984-95 (numbers in thousands)

\section{Occupation}

\section{Change in employment}

\section{Cashiers}

Registered nurses 1984-95

Janitors and cleaners Number Per cent

Truckdrivers

Waiters and waitresses

Wholesale trade

Nursing aides, orderlies, and attendants

Salespersons, retail

Accountants and auditors

$\begin{array}{ll}556 & 29.8 \\ 452 & 32.8 \\ 443 & 15.1 \\ 428 & 17.2 \\ 424 & 26.1 \\ 369 & 29.6 \\ 348 & 28.9 \\ & \\ 343 & 12.6 \\ 307 & 34.8\end{array}$

\section{Data from ref. 2.}

dustries and 750 occupations making it the most sophisticated analytical econometric occupational model in the world.

From a base of 107 million in 1984, total employment in the United States is expected to grow to 130 million in 1995 , a growth of about 15 per cent. This represents a slowdown in the growth of the previous decade. Service industries which account for 7 out of 10 jobs are expected to continue to grow more rapidly than manufacturing and other industries. This growth will be fuelled by rising living standards, in turn leading to greater demand for health care, entertainment, banking and insurance services, and these sectors are expected to account for nine out of ten new jobs over this period. Employment in US goods producing sectors is also expected to grow, albeit at a much slower rate of only about 6 per cent. This growth rate, however, in part represents a recovery after the recession of 1981-82 and in 1995 employment is likely to be only slightly higher than that in 1979. The main engine of this growth is expected to be increasing capital spending and defence expenditure, with the computer, materials handling equipment and scientific and instrument industries particularly benefiting and showing output growth significantly in excess of projected productivity gains. The sectors showing decline include basic industries such as mining, where productivity gains, improvements in technology and in some activities rising import penetration will reduce employment. Agricultural employment is also expected to continue its longterm decline (Fig. 1).

One thing that is not clear from these figures, though, is the extent to which they represent a statistical name change. In the United Kingdom, for example, almost half the growth in service jobs (actual and projected) through the 1980 s is expected to be due to the goods producing sectors 'contracting out' activities such as wholesaling, catering, transport and professional services to specialist service sector companies. Thus a crude interpretation of the figures, in the UK case at least, overemphasizes the so called decline of manufacturing and the growth of services. But it is not clear whether the United States is following a similar trend.

A more balanced perspective can be had from an assessment of occupational change, although these figures are in part derived from industrial or sectoral trends. The occupations with the highest growth rates will be paralegal, computing and electronics staff, and medical assistants all showing increases of 50 per cent or more in employment levels. In absolute terms, then cashiers, nurses, cleaners, truck drivers and waiters are all groups expecting to expand their employment by 400,000 jobs or more (Table 1). A detailed analysis shows no general upgrading of jobs to graduate status, there being no more growth
Projected change in employment, 1984-95 (millions) $\begin{array}{llllllllll}-1 & 0 & 1 & 2 & 3 & 4 & 5 & 6 & 7 & 8\end{array}$ $-1$

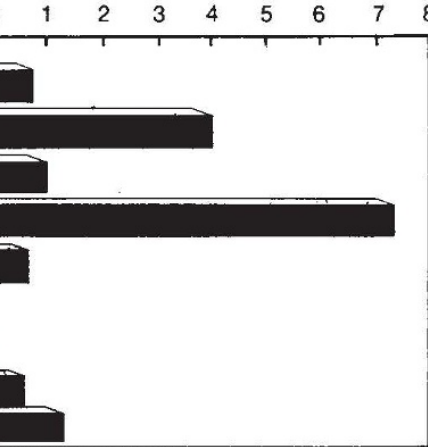

ufacturing

Department of Labor study show that some

among jobs requiring extensive training than those requiring little formal training, and only one in four of the new jobs is expected to require a college degree. The occupations showing the largest decline are stenographers (down 40 per cent), shoe machinists (down 32 per cent), and railroad operators (down 26 per cent), these are to be found either in the declining sectors or are being severely affected by technological change, the stenographers being a prime example.

For scientists and engineers the best prospects are for those related to computing and electronics, and engineers in general are expected to have better job prospects than scientists although both groups are expected to show at least average employment growth. Military technology, the automation of industrial production, the development of energy sources, basic research, and environmental protection are all activities generating improved employment prospects for such staff.

Overall the rate of population growth in the United States is slowing down and the total labour force is expected to grow a little slower than will employment opportunities. The final balance in 1995 will be subject to the many uncertainties in the economy, as well as the rate of technological change, and changing social habits and priorities. Nevertheless, the outlook in terms of job opportunities is expected to continue to improve, and will encompass a wide range of skill levels and locations. Flexibility will be the key need for job seekers operating in such a rapidly changing market

1. Pearson, R. Nature 323, 94 (1986).

2. Occupational Projections and Training Data (US Department of Labor, 1986).

Richard Pearson is at the Institute of Manpower Studies, Mantell Building, University of Sussex, Falmer, Brighton BN1 9RF, UK. 